\title{
Da guerra às drogas à guerra ao vírus: necropolítica e resistência na Cracolândia
}

\author{
YGor DiEgo DELGADO ALVES \\ Universidade Federal de São Paulo, São Paulo, São Paulo, Brasil \\ antropologiaygor@yahoo.com.br \\ PEDRO PAUlo GOMES PEREIRA \\ Universidade Federal de São Paulo, São Paulo, São Paulo, Brasil \\ pedropaulopereira@hotmail.com
}

DOI 10.11606/issn.2316-9133.v29isuplp319-328

resumo $\mathrm{O}$ artigo tem por objetivo analisar as formas de resistência presentes na Cracolândia paulistana diante da pandemia da Covid-19 e de suas consequências. Para tanto, nos valemos de documentos públicos e artigos acadêmicos sobre os temas abordados no sentido de descrever as ações de resistência, por parte de militantes e outros frequentadores daquele território. A análise dessas ações, ante a repressão policial e o ataque midiático à Cracolândia, foi empreendida tendo por referencial teórico as ideias de Achille Mbembe. Vimos como, apesar de marcados pela necropolítica, os usuários de crack, com militantes de diversas entidades e coletivos, negam diariamente, por vezes de modo festivo, o necropoder. Resistem por suas vidas com táticas de contenção da letalidade materializadas em oficinas de autocuidado, distribuição de alimentos e iniciativas de ajuda mútua.

palavras-chave Cracolândia. Necropolítica. Covid-19. Resistência.

From the war on drugs to the war on the virus: necropolitics and resistance in Cracolândia, São Paulo

abstract The article aims to analyze the forms of resistance present in São Paulo's Cracolândia in the face of the Covid-19 pandemic and its consequences. To this end, we use public documents and academic articles on the topics addressed in order to describe the actions of resistance, by militants and other regulars in that territory. The analysis of these actions, in the face of police repression and the media attack on Cracolândia, was undertaken with the theoretical framework of Achille Mbembe's ideas. We have seen how, despite being 
marked by the necropolitics, crack users, together with militants from different entities and collectives, daily deny, sometimes in a festive way, necropower. They resist for their lives with tactics to contain lethality materialized in self-care workshops, food distribution and mutual aid initiatives.

keywords Cracolândia; Necropolitics; Covid-19; Resistance

\section{De la guerra contra las drogas a la guerra contra el virus: necropolítica y resistencia en la Cracolândia, São Paulo \\ resumen El artículo analiza las formas de resistencia presentes en la Cracolandia} de São Paulo frente a la pandemia delCovid-19 y sus efectos. Hemos utilizado documentos públicos y artículos académicos sobre los temas tratados para describir las acciones de resistencia de los militantes y otros frecuentadores de ese territorio. El análisis de estas acciones, ante la represión policial y el ataque de los medios de comunicación a Cracolândia, se realizó con las ideas de Achille Mbembe como referencia teórica. Vimos cómo, a pesar de estar marcados por la necropolítica, los usuarios de crack, junto con militantes de diversas entidades y colectivos, niegan a diario, a veces festivamente, el necropoder. Resisten por sus vidas con tácticas de contención letal materializadas en talleres de autocuidado, distribución de alimentos e iniciativas de ayuda mutua.

palabras clave Cracolândia. Necropolítica. Covid-19; Resistencia.

\section{Introdução}

Objeto de intervenções sucessivas das três esferas de governo relacionadas com as pessoas que fazem uso do crack nas imediações da região conhecida como Boca do Lixo, centro da cidade de São Paulo, a Cracolândia tem se mostrado resiliente às tentativas reiteradas de expulsão. Estas ações, que muitas vezes primaram pela violência e falta de planejamento, têm obtido efeitos em deslocar a cena de uso e em conformá-la, cada vez mais tão-somente, em local, a despeito de relações de tipo comunitário (ALVES, 2014), dedicado à convivência entre consumidores de álcool e crack (ALVES; PEREIRA, 2019). Procuramos investigar como, no contexto da Covid-19, as representações negativas em torno daquele espaço e daquelas pessoas são reativadas em um discurso de contaminação, perigo e morte, em meio ao desmonte da rede de atendimento local a usuários de crack, para imediatamente serem subvertidas por práticas de resistência.

A produção da morte em larga escala é, em Achille Mbembe (2012), o centro do que denomina como necropolítica: uma das características de um mundo em crise sistêmica. $\mathrm{O}$ autor camaronês, historiador e cientista social, busca atualizar a crítica foucaultiana no sentido de a tornar uma ferramenta de análise para fenômenos da periferia do capitalismo. Segundo sua elaboração, nessa periferia, a biopolítica, que nas formulações de Foucault seria 
dedicada à produção e manutenção da vida, cede lugar à produção da morte - a necropolítica. Formam-se massas supérfluas vivendo nos espaços marginalizados das grandes cidades, na precariedade e desprezadas pelo arranjo socioeconômico. A necropolítica, ao invés de cultivar a vida, torna os massacres vitais e objetiva a "destruição material dos corpos e populações humanas julgados como descartáveis e supérfluos” (MBEMBE, 2012, p. 135).

A existência cotidiana na Cracolândia se apresenta, em Calil (2016), como uma atitude política limite, em que a resistência se expressa por um saudável interesse em sobreviver. Os próprios modos de ocupação do local também seriam, em Rui (2014), marcados por uma ocupação itinerante como forma de resistência à repressão policial. Em Ribeiro Júnior (2016) podemos ver como a criminalização discricionária de certas drogas é utilizada como dispositivo de controle social; e como, neste sentido, a utilização das políticas criminais sobre drogas passa a ser um dispositivo que justifica violências cometidas com o escopo de realizar o controle (de vida e de morte) de determinados grupos e pessoas. Para Oliveira e Ribeiro (2018) a distribuição da morte, como exercício organizado do poder de Estado em territórios de guerra às drogas, e a necropolítica percorrem as narrativas televisivas e distribuem o medo por meio de uma economia de violências. A desumanização e a segregação espacial marcam, em Neto (2018), a Cracolândia, e ambas tornam seus habitantes objetos de violência, que só é possível a partir da construção de identidades sociais baseadas na morte dos indivíduos. Naquele território, que o autor considera como sendo uma fronteira urbana marcada pela necropolítica, se fundem os discursos sanitaristas e policiais. Discursos esses que, ainda em Neto (2018), tornam possível que a Cracolândia seja caracterizada pelo confinamento forçado dos considerados indesejados pela sociedade: os negros, os pobres, as pessoas em situação de rua e os dependentes químicos.

MacRae, Tavares e Nuñez (2013) nos mostram como, há anos, a Cracolândia é o local por excelência em que se fixa uma falsa epidemia (do crack) e que, desde meados dos anos 1990, nos assombra, por meio de diversos meios de comunicação, com sua associação à ideia de morte. MacRae, particularmente, aponta que: “[e]m relação a esse termo 'epidemia do crack', eu, enquanto antropólogo, fico com os dois pés atrás, porque o termo 'epidemia' remete ao biológico, como se houvesse um vetor que a difundisse." Ainda segundo os autores, é desde a década de 1980, durante o governo do direitista Ronald Reagan, que, nos Estados Unidos, o ambiente de pânico em torno dessa pretensa epidemia serviu de incentivo à guerra às drogas (Ibidem, p. 45).

Para Medeiros (2015) a ideia de uma epidemia do crack ajuda a demarcar o que a autora chama de "territórios crônicos na cidade", reservados aos pobres, àqueles sem vínculo formal de trabalho ou familiar. Personificados por narrativas sobre monstros, marcados, sujos, queimados e magros, que testemunhariam o potencial destrutivo do crack em uma monstruosidade desmedida, quase desumana, que provoca asco e horror; além do mórbido 
"desafio do controle, domínio, da subordinação e até mesmo da sedução para destruir o monstro" (MEDEIROS, 2015, p. 214).

Para traçarmos o panorama desejado, valemo-nos de: 1) trabalhos acadêmicos sobre a Cracolândia; 2) matérias jornalísticas publicadas sobre o período; 3) textos e declarações de ativistas nas redes sociais; e 4) entrevistas com profissionais a serviço da administração municipal. Assim, acreditamos ter podido delinear um brevíssimo panorama das repercussões na mídia do avanço da Covid-19 na Cracolândia, e das ações recentes de resistência aos avanços do desmanche promovido pelo poder público naquele território. Para enfim, cotejá-las com a produção acadêmica dedicada ao assunto com vista a sua análise, de forma inédita, a partir das ideias de Achille Mbembe (2012) sobre necropoder e necropolítica. Procuramos investigar como, no contexto da Covid-19, as antigas representações negativas em torno de uma improvável epidemia do crack são reavivadas em um discurso de contaminação e perigo; que acabam por subscrever o abandono dessas pessoas à própria sorte, e ensejar formas de resistência.

\section{"Cracolândia lotada gera preocupação em meio à pandemia de coronavírus."}

O título desta seção é a chamada para uma matéria exibida no dia 20 de março de 2020, no programa televisivo Cidade Alerta Record (2020). É uma notícia relativamente precoce nas preocupações da Cidade de São Paulo e do estado de São Paulo com relação à pandemia que se instalava. Ainda mais se considerarmos que as aulas na rede pública municipal e estadual só seriam interrompidas, por conta do risco de contaminação pela Covid-19, três dias depois, em 23 de março. A descrição dessa matéria jornalística na página do YouTube traz algumas indicações sobre os motivos que animam a escolha dessa pauta específica: "O helicóptero da Record TV flagrou, na tarde desta sexta-feira (20), a região da Cracolândia, na região central de São Paulo, repleta de usuários de drogas em contato constante, o que gera preocupação em meio ao avanço da contaminação." São 13 minutos e 32 segundos de imagens aéreas que mostram, em tom de denúncia e alarme, o fluxo de usuários de crack no fim de uma tarde de sexta-feira. Alguns pontos poderiam ser brevemente analisados nessa chamada: 1) o fato de ter sido baseada em imagens aéreas; 2) as ideias de contato e contaminação. Sabemos que os frequentadores da Cracolândia paulistana são avessos a produção de imagens no local, fato bastante razoável dada a ilegalidade e o estigma (ADORNO et. al., 2013) que ronda o consumo do crack e o próprio território. Em segundo lugar cabe observar como as ideias de contato e contaminação dialogam com antigos temores em torno de uma há muito desmentida epidemia do crack (MEDEIROS, 2015). 
A mensagem que se procura transmitir com a matéria jornalística do Cidade Alerta Record (2020) é muito clara, tanto que, logo em seu início, aos 24 segundos de exibição, após observar que a Cracolândia estava "lotada no meio da pandemia do coronavírus", o apresentador faz o que parece ser um gravíssimo alerta: "São pessoas que podem levar o vírus para tudo quanto é lado.” É como se o caráter gregário do consumo do crack no centro de São Paulo pudesse fundir as duas epidemias: do crack e da Covid-19. Alguns segundos depois, após caracterizar as pessoas e lançar o aviso de perigo, o apresentador cobra "se existe algum plano a ser feito com essa gente”.

\section{Resistência à necropolítica em tempos da Covid-19}

Era uma sexta-feira de carnaval de 2020. Na rua Helvétia, em frente à antiga tenda do programa De Braços Abertos (DBA), começa a se formar uma concentração de pessoas no interior do fluxo de usuários de crack: era o carnaval da Cracolândia. Desde 2014, existe o bloco carnavalesco Blocolândia. Nele os foliões se apresentam fantasiados, cobertos de purpurina, com perucas coloridas e, nas mãos, no lugar dos usuais cachimbos, instrumentos musicais e adereços dão vida ao samba. Assim foi das 16 até as 18 horas, momento da dispersão, e assim estava a Cracolândia antes do alarme em torno da pandemia da Covid-19, que viria soar, na cidade de São Paulo, logo após o carnaval. Foi uma tarde de clima quente, propício à folia, e a chuva, que prometia se fazer presente durante o desfile, foi condescendente. Ao contrário da polícia militar (PM) que havia determinado o cancelamento do carnaval de rua do Blocolândia, comunicado publicado no Diário Oficial do Município, na data do evento: 21 de fevereiro. A jornalista Tahiane Stochero (2020), do site G1, procurou saber dos organizadores qual seria sua posição frente a decisão da PM, ao que Raphael Escobar respondeu em tom questionador: "Vamos sair de qualquer jeito, faça chuva ou faça bomba. Estranhamos essa proibição, assim do nada. A quem interessa proibir um desfile? Todos os 900 blocos registrados podem desfilar, menos nós? Por quê?". Assim somos introduzidos a um dos mais presentes ativistas que passaram a ter um papel militante na região, principalmente após o surgimento do DBA. Escobar faz parte de uma legião de militantes - em boa parte funcionários e ex-funcionários dos governos municipal e estadual, que trabalham ou trabalharam com os frequentadores daquele espaço - que se aglutinam em torno de entidades e coletivos como é o caso da Craco Resiste a que pertence Escobar.

Não só a Craco Resiste participou da organização do carnaval na Cracolândia, outros grupos como Coletivo Tem Sentimento (doravante CTS), da assistente social Carmen Lopes, que fez os abadás do Blocolândia com apoio do Teatro de Container, se envolveram na preparação da festa. Para concluir esse feito o CTS teve de percorrer algumas centenas de metros, e dois pares de anos. Fundado em janeiro de 2016, o CTS contava apenas com o trabalho voluntário de Carmen que passou a desenvolver atividades no largo General 
Osório, distante 500 metros, 6 minutos a pé, da antiga tenda do DBA, onde Carmen iniciou, ainda como estudante, sua carreira de assistente social. São atividades voltadas ao que Carmen chama de autocuidado, que atentam para os cabelos, unhas, rosto e pés de mulheres transexuais e não trans. Em pouco tempo viram a necessidade de geração de renda para as participantes que se uniam em torno dessas oficinas realizadas no largo General Osório, aos sábados pela manhã. Assim uma outra oficina foi criada e a chamaram de moda justa. Com máquinas de costura doadas e ocupando o andar inteiro de um edifício abandonado, ao lado do Teatro de Container, em frente ao mesmo largo General Osório, pertencente a Companhia Mungunzá, foi possível iniciar trabalhos de corte, costura, customização e artesanato; e, finalmente, os abadás do Blocolândia em 2020.

Após o término do carnaval, as notícias em torno da Covid-19 se avolumam semana após semana. Enquanto parte importante da grande mídia pedia providências do poder público, Carmen Lopes vinha reivindicando, em seu perfil no Facebook, melhorias no acesso à água para dos frequentadores da Cracolândia. Em dez dias, bebedouros foram instalados pela prefeitura na praça Princesa Isabel, importante ponto de concentração de moradores de rua e usuários de crack, e próximo ao largo Gen. Osório, local das oficinas do CTS. A escassez de alimentos no "fluxo", nome dado a concentração de usuários de crack, e a preocupação dessas pessoas com a pandemia fazem com que Carmen peça por alimentos que possam ser doados, posteriormente, pelo Coletivo (LOPES, 2020). Dois dias após esse apelo, em 27 de março, centenas de quilos de alimentos orgânicos são levados por voluntários à sede da Cia Pessoal do Faroeste, localizada na rua do triunfo 301, em frente ao largo Gen. Osório, para serem retirados por famílias de pensões do entorno do fluxo, prostitutas e travestis, que também tiveram acesso a itens de higiene pessoal. Essa distribuição de alimentos e artigos de higiene se iniciou numa sexta-feira. Na terça-feira subsequente, o CTS distribuía as primeiras refeições aos moradores de rua e usuários de crack da praça Princesa Isabel. No dia seguinte, o mesmo Coletivo em parceria com: 1) Pagode na Lata, um projeto com a proposta de promover a redução de danos através da arte, formado por ex-trabalhadores na Cracolândia; 2) Paulestinos, dupla de artistas gráficos que trabalham com lambe-lambe nos postes e muros da cidade; e 3) Makers Contra a Covid-19, um grupo, inspirado nas experiências chinesa e italiana, dedicado a imprimir equipamentos de segurança como as Máscaras Faciais de Proteção para uso profissional, fez outra ação naquele território. Dessa vez, puderam ser distribuídos “[...]cerca de 400 garrafas de água, 250 kits de higiene e garrafas com água potável e detergente para higienização das mãos da população que vive e mora na rua” (LOPES, 2020b). São práticas que remetem ao que Bortolozzi Junior (2018) identifica, a partir da crise do proibicionismo, como ações de redução de danos, que podem significar táticas de contenção da letalidade e de resistência à necropolítica. Em um dos hotéis que abrigam os antigos beneficiários do programa De Braços Abertos, localizado próximo a 
Cracolândia, uma técnica que ali trabalha desde o ano de 2016, ao nos relatar, no final do mês de maio de 2020, a deterioração das condições de atendimento das pessoas que lá residem, afirmou que: "Agora na pandemia, nós estamos sendo assistidos, em relação ao cuidado com os moradores, predominantemente por doações[...]”. São as mesmas distribuídas por Carmen e seu Coletivo Tem Sentimento.

Nos dias que se seguem até a conclusão deste artigo, as ações continuaram e, por vezes sofreram repressão policial. No dia 23 de abril, em Lemes (2020), é feita uma denúncia sobre os ataques com bombas de gás lacrimogêneo da Polícia Militar contra os frequentadores da Cracolândia, durante a distribuição de comida que comumente é realizada por algumas organizações da sociedade civil, na hora do almoço. Medeiros (2017) nos mostra como a gestão e a gerência de mortos, vinculados ao tráfico de drogas, em uma divisão de homicídios da polícia civil na região metropolitana do Rio de Janeiro, se dá no âmbito de uma guerra, com tecnologias de governo de uma necropolítica. $\mathrm{Na}$ Cracolândia, os ataques às pessoas que distribuem comida são sistemáticos e, aparentemente, obedecem a uma lógica que visa impossibilitar a vida naquele espaço. Uma violência cotidiana que vem como resposta ao clamor midiático por medidas contra o potencial perigo que os frequentadores daquele lugar poderiam representar à saúde pública em tempos de Covid-19. Vimos como desde muito cedo nas preocupações da cidade com a pandemia que notícias alarmantes são veiculadas sobre esse ambiente em especial.

\section{Um conto de duas epidemias}

Após a cobrança por medidas do poder público feita precocemente, dentro das preocupações da cidade com a Covid-19, com relação à possibilidade de contágio urbano a partir de uma população específica, os usuários de crack, uma maquinaria de controle, domínio e subordinação (MEDEIROS, 2015) seria colocada em movimento para deter esse perigoso vetor (MACRAE; TAVARES; NUÑEZ, 2013). As matérias se sucedem em diversos veículos de mídia, e permanecem sendo publicadas nos dias seguintes. Ao terminar o mês de março, no dia 31, trabalho jornalístico da Rede Globo, novamente com imagens de helicóptero, ressalta que os consumidores de crack estão aglomerados "trocando cachimbos" e sem "nenhuma preocupação com o contágio pelo coronavírus" (G1, 2020).

No dia 8 de abril foi registrada a primeira morte suspeita de Covid-19 na Cracolândia. As notícias sobre aglomerações naquele espaço vão num crescendo, acompanhando o noticiário sobre a Covid-19, até que em 13 de maio, em nome do combate a "disseminação de coronavírus”, o Ministério Público de São Paulo pede à prefeitura e ao governo estadual para esvaziar a Cracolândia, levando a guerra às drogas ao estatuto de solução final. Pedido negado pela Justiça no dia seguinte (BALANÇO GERAL, 2020). O caso expõe como os usuários de crack são deixados à própria sorte, abandonados em um "território crônico" 
(MEDEIROS, 2015), em meio a certo clima, promovido pela mídia, em que são retomados antigos espectros em torno da epidemia do crack. Uma falsa condição de contágio em massa de pessoas pelo vício numa droga tida como mortal, e que teria por vetor (MACRAE; TAVARES; NUÑEZ, 2013) uma espécie de monstro semimorto ou zumbi (PINTO, 2015; ALVES, 2017). Trata-se de destruir o monstro e impedir que um novo espectro ronde a cidade, o espectro do craqueiro contaminado.

Ao se referir a categoria necropolítica de Achile Mbembe para analisar os efeitos de poder do dispositivo das drogas no contexto brasileiro, Bortolozzi Junior (2018) identifica, a partir da crise do proibicionismo, a emergência de saberes e práticas, como são as ações de redução de danos, vistas nesse artigo nas iniciativas de distribuição de alimentos e itens de higiene pessoal, que podem significar táticas de contenção da letalidade e de resistência ao atual modelo necropolítico. A "guerra às drogas" (somada a precarização de políticas sociais) cria, para Benicio et al (2018), sujeitos matáveis, vítimas de investimentos equivocados em políticas de segurança pública na militarização das margens urbanas. Como tem se mostrado ser o caso da Cracolândia que, para Neto (2018), foi transformada em uma fronteira urbana marcada pela necropolítica. Uma produção da morte que não ocorre sem a resistência cotidiana dos usuários de crack, juntamente com os militantes das diversas entidades e coletivos que aqui mencionamos.

A resistência se expressa como negação diária da necropolítica, por vezes de modo alegre e glorioso, como foi no carnaval do Blocolândia. Apesar da proibição policial o carnaval no "fluxo" aconteceu, ainda acontecem diariamente ações de autocuidado, auxílios e ajudas as mais diversas. A alimentação, com distribuição de comida pronta ou mantimentos, possível reflexo de relações comunitárias pré-existentes (ALVES, 2014), também persevera a dizer que aqueles sujeitos não são matáveis e tampouco irão se entregar como objetos passivos de uma política que se converte em trabalho de morte. O necropoder, ao se fazer valer na Cracolândia, dá de encontro com as táticas de contenção da letalidade que buscamos descrever brevemente.

\section{Referências Bibliográficas}

ADORNO, Rubens Camargo Ferreira; RUI, Taniele; SILVA, Selma Lima; MALVASI, Paulo Artur; VASCONCELLOS Maria da Penha; GOMES, Bruno Ramos; CALIL, Thiago Godoi. (2013). "Etnografia da cracolândia: notas sobre uma pesquisa em território urbano”. Saúde \& Transformação Social, v. 4, n. 2, p. 04-13, 2013.

ALVES, Ygor Delgado. (2014). “A Cracolândia como 'communitas' e o frade craqueiro”. In: RAMMINGER, Tatiana; SILVA, Martinho (Orgs). In: Mais substâncias para o trabalho em saúde com usuários de drogas. Porto Alegre: Rede UNIDA. 
ALVES, Ygor Delgado. (2017). Jamais fomos zumbis: contexto social e craqueiros na cidade de São Paulo. SciELO-EDUFBA.

ALVES, Ygor Delgado; PEREIRA, Pedro Paulo Gomes. (2019). Sob fogo cruzado: antecedentes, construção e desmonte do programa De Braços Abertos na Cracolândia paulistana. Salvador: EDUFBA.

BALANÇO GERAL. (2020). Justiça nega pedido do Ministério Público para esvaziar a Cracolândia em SP. Youtube, 14 maio 2020. Disponível em: https://www.youtube.com/watch?v=hom6YPYH3yQ. Acesso em: 14 maio 2020.

BENICIO, Luis Fernando de Souza; BARROS, João Paulo Pereira; RODRIGUES, Jéssica Silva; SILVA, Dagualberto Barboza da; LEONARDO, Camila dos Santos; COSTA, Aldemar Ferreira. (2018). "Necropolítica e pesquisa-intervenção sobre homicídios de adolescentes e jovens em Fortaleza, CE”. Psicologia: Ciência e Profissão, v. 38, n. SPE2, p. 192-207.

BORTOLOZZI JUNIOR, Flávio. (2018). Resistir para re-existir. criminologia (d)e resistência diante do governamento necropolítico das drogas. 294f. Tese de Doutorado em Direito. Curitiba: Universidade Federal do Paraná.

CALIL, Thiago Godoi. (2016). "Relatos e imagens da cracolândia: modos de vida e resistência na rua". Cadernos de Arte e Antropologia, v. 5, n. 2, p. 91-102.

CIDADE ALERTA RECORD. (2020). "Cracolândia lotada gera preocupação em meio à pandemia de coronavírus”. Youtube, 20 mar. 2020. Disponível em: https://www.youtube.com/watch?v=KYqohwAQHWE . Acesso em: 11 maio 2020.

G1. (2020). Coronavírus não muda rotina nas cracolândias. Globo.com, 31 mar. 2020. Disponível em: http://g1.globo.com/sao-paulo/videos/v/coronavirus-nao-mudarotina-nas-cracolandias/8446857/ . Acesso em: 14 maio 2020.

LEMES, Conceição. "Morador: 'Contra o coronavírus, aqui na Cracolândia, é bomba, muito bomba!”. VIOMUNDO, 24 ABR. 2020. Disponível em: https://www.viomundo.com.br/denuncias/morador-contra-o-coronavirus-aqui-nacracolandia-e-bomba-muito-bomba-video.html. Acesso em: 14 maio 2020.

LOPES, Carmen. (2020a). "Para as pessoas que tem me perguntado sobre o território da Cracolândia”. São Paulo, 25 mar. 2020. Facebook: Carmen Lopes. Disponível em: https://www.facebook.com/carmen.lopes.7547 Acesso em: 29 maio 2020.

LOPES, Carmen. (2020b). Ação no território da Cracolândia hoje!! São Paulo, 1 abr. 2020b. Facebook: Carmen Lopes. Disponível em: https://www.facebook.com/carmen.lopes.7547 Acesso em: 29 maio 2020.

MACRAE, Edward.; TAVARES, Luiz Alberto.; NUÑEZ, Maria Eugênia. (Orgs). (2013). Crack: contextos, padrões e propósitos de uso. Salvador: EDUFBA. 
MBEMBE, Achille. (2016). "Necropolítica: biopoder, soberania, estado de exceção, política da morte”. Arte \& Ensaios, vol.32, pp.123-151.

MEDEIROS, Flavia. (2017). "A necropolítica da 'guerra': tecnologias de governo, 'homicídios' e 'tráfico de drogas' na região metropolitana do Rio de Janeiro”. Abya Yala, v. 2, n. 2-2018, 2017.

MEDEIROS, Regina. (2015). “A epidemia do crack a quem interessa”. (2015). In: SUDBRACK, Maria Fátima Olivier; CONCEIÇÃO, Maria Inês Gandolfo; SILVA, Isabela Machado; LORDELLO, Sílvia Renata (Orgs). ABRAMD: compartilhando saberes, v. 1, p. 208-224.

NETO, Olegario da Costa Maya. (2018). "Necropolítica da colonialidade no Brasil: segregação e desumanização no Hospital Colônia de Barbacena e na Cracolândia, em São Paulo”. Meridional. Revista Chilena de Estudios Latinoamericanos, n. 11, p. 149-177.

OLIVEIRA, Nathália; RIBEIRO, Eduardo. (2018). "O massacre negro brasileiro na guerra às drogas". SUR 28, v. 15, n. 28, pp35-43.

PINTO, Rodrigo Teixeira. (2015). "Transformando-se em zumbi: a representação monstruosa do usuário de crack”. Sociologias Plurais, vol.3, n.1, p.106-116.

RIBEIRO JÚNIOR, Antônio Carlos. (2016). "As drogas, os inimigos e a necropolítica”. Cadernos do CEAS: Revista crítica de humanidades, n. 238, p. 595-610.

RUI, Taniele. (2014). “Usos da 'Luz' e da 'Cracolândia': etnografia de práticas espaciais”. Saúde e Sociedade, vol.23, p. 91-104.

STOCHERO. Tatiana. "PM cancela autorização para bloco desfilar na Cracolândia; 'Vamos sair, faça chuva ou faça bomba', diz organizador”. G1, 21 fev. 2020.

\section{sobre os autores}

\section{Ygor Diego Delgado Alves}

Pós-doutorando em Saúde Coletiva na Universidade Federal de São Paulo, com doutorado em Antropologia pela Universidade Federal da Bahia, e mestrado e graduação em Ciências Sociais pela PUC São Paulo.

\section{Pedro Paulo Gomes Pereira}

Professor Livre Docente da Universidade Federal de São Paulo. Possui título de doutor e mestre em Antropologia pela Universidade de Brasília. 